\title{
Oil Price Shocks and Stock Market Returns in Oil-Exporting Countries: The Case of GCC Countries
}

\author{
Mohamed El Hédi AROURI \\ LEO-Université d'Orléans \& EDHEC \\ E-mail: mohamed.arouri@univ-orleans.fr \\ Amine Lahiani \\ LEO-Université d'Orléans \& ESC Rennes School of Business \\ E-mail: amine.lahiani@univ-orléans.fr \\ Makram BELLALAH \\ University of Amiens, CIIRSEA-FOM \\ E-mail: Makram.bellalah@u-picardie.fr
}

\begin{abstract}
Using linear and nonlinear models, this paper investigates the responses of stock markets in GCC countries to oil price shocks. Our findings show that stock market returns significantly react to oil price changes in Qatar, Oman, Saudi Arabia and UAE. In addition, we establish that the relationships between oil prices and stock markets in these countries are nonlinear and switching according to the oil price values. However, for Bahrain and Kuwait we found that oil price changes do not affect stock market returns.
\end{abstract}

Keywords: GCC stock markets, Oil prices, Nonlinear models

JEL classifications: G12, F3, Q43.

\section{Introduction}

In the literature, there are many studies on the effects of oil price shocks on economic activity. These studies have mainly showed that oil prices significantly impact economic variables in most developed and emerging countries [Cunado and Perez de Garcia (2005), Balaz and Londarev (2006), Gronwald (2008), Cologni and Manera (2008) and Kilian (2008)]. Moreover, recent papers have established that the responses of economic variables to oil price changes are likely to be asymmetric and signs of nonlinearities have been reported [Hamilton (2003), Zhang (2008), Lardic and Mignon (2006, 2008), and Cologni and Manera (2009)]. Surprisingly, there has been relatively little work done on the relationships between oil price changes and stock market returns. In addition, most of these works have focused on few developed countries. As for emerging stock markets, very few studies have been carried out.

In theory, there are several channels through which oil prices may affect stock market prices. The most invoked rational of using oil price changes as a factor affecting stock market returns is that value of stock equals discounted sum of expected future cash-flows. These cash-flows are affected by macroeconomic events that possibly can be influenced by oil shocks. Thus, oil price fluctuations may influence stock market returns. Most of previous studies have investigated this relationship within the framework of linear models using low frequency (monthly or quarterly) data from net oil importing countries. Using weekly data and nonlinear models, the present paper investigates the short-run relationship between oil price shocks and stock markets in the Gulf Cooperation Council (GCC) countries.

The GCC was established in 1981 and it includes six countries: Bahrain, Oman, Kuwait, Qatar, Saudi Arabia and the United Arab Emirates (UAE). Studying the link between oil prices and stock markets in GCC countries is interesting for several reasons. In fact, GCC countries have attracted increasing attention in recent years. In the wake of high oil prices since 2003, they have developed into hubs of global economic growth. They have also become important international investors and trade partners, and play a crucial role in world energy markets. Indeed, together, GCC countries produce about $20 \%$ of all world oil, control $36 \%$ of world oil exports and possess $47 \%$ of the world oil proven. Oil exports largely determine earnings, government budget revenues and expenditures and aggregate demand. Overall, GCC stock markets are limited by several structural and regulatory weaknesses: relatively small numbers of listed firms, large institutional holdings, low sectoral diversification, and several other deficiencies. In recent years, however, a broad range of legal, regulatory, and supervisory changes has increased market transparency. Finally, even 
if GCC countries have several economic and political characteristics in common, they have different oil dependence degrees and efforts to diversify and liberalize the economy.

The pioneering paper by Jones and Kaul (1996) investigates the responses of major developed stock markets (Canada, UK, Japan and US) to oil price shocks. They found that for the US and Canada this reaction can be accounted for entirely by the impact of the oil shocks on cash flows. The results for Japan and the UK were inconclusive. Huang et al. (1996) show a significant link between some American oil company stock returns and oil price changes. However, they find no evidence of a relationship between oil prices and the S\&P500. In contrast, Sadorsky (1999) shows a significant relationship between oil price changes and aggregate stock returns in the US. In particular, he shows that oil price shocks have asymmetric effects: positive oil shocks have a greater impact on stock returns and economic activity than do negative oil price shocks. Relying on nonlinear causality tests, Ciner (2001) provides evidence that oil shocks affect in a non linear manner stock returns in the US, which is consistent with the documented influence of oil on economic activity.

In the recent years, some papers have tented to focus on major European, Asian and Latin American emerging markets and showed significant relationships between oil price changes and emerging stock markets. For instance, Papapetrou (2001) shows a significant relationship between oil price changes and stock markets in Greece. Basher and Sadorsky (2006) reach the same conclusion for other emerging stock markets using an international multifactor model. However, less attention has been given to smaller emerging markets, especially in the GCC countries where share dealings is a relatively recent phenomenon. Using VAR models and cointegration tests, Hammoudeh and Eleisa (2004) show that there is a bidirectional relationship between Saudi stock returns and oil prices changes. All the previous findings also suggest that the other GCC markets are not directly linked to oil prices and are less dependent on oil exports and are more influenced by their own domestic factors. Bashar (2006) employs VAR analysis to study the effect of oil price changes on GCC stock markets, and shows that only Saudi and Oman markets have predictive power of oil price increase.

Hammoudeh and Choi (2006) examined the long-run relationship among the GCC stock markets in the presence of the US oil market, the S\&P 500 index and the US Treasury bill rate. They found that the T bill rate has direct impact on these markets, while oil and S\&P 500 have indirect effects. Using nonlinear cointegration tests, Maghyereh and Al-Kandari (2007) show that, in the long-run, oil price impact the stock price indices in GCC countries in a nonlinear fashion. Finally, In a more recent study, Arouri and Jouini (2009) examine the short-run relationships between oil prices and GCC stock markets. Using a non parametric method -a local polynomial kernel regression of order 2 with a Gaussian kernel- they show that there are some signs of nonlinearities in the link between oil and stock market returns in Qatar, Oman, and UAE. In fact, their results establish that the relationships between oil prices and stock markets in these countries are asymmetric and switching according to the oil price change values. However, the method they use does not precise the analytical form of this nonlinear link, and thus results can be hardly used in portfolio management or policy decision process. For Bahrain, Kuwait, and Saudi Arabia the authors found that oil price changes do not affect stock market returns.

To sum up, the findings of the previous studies on the impact of oil price changes on GCC stock markets are too heterogeneous to lead to a general consensus. These findings are puzzling because the GCC countries are strongly oil exporters and share several similarities in their economic structures. The conclusions of these studies could be due to the fact that the tests they rely on are not powerful enough to detect nonlinear linkages. As we have mentioned above, recent papers argue that there are some signs of nonlinearities in the relationship between oil prices and the economic activity. This suggests that asymmetric linkages between oil prices and the stock market could be uncovered. This article extends the understanding of the relationship between oil prices and the stock market in GCC markets by testing for linear and nonlinear short-run relationships.

The rest of the paper is organized as follows. Section 2 presents the data. The methodology and empirical results are discussed in section 3. Summary conclusions and policy implications are provided in Section 4.

\section{Data}

The aim of this article is to investigate the short-term link between oil prices and stock markets in GCC countries. Unlike previous studies which use low frequency data (yearly, quarterly or monthly), we use weekly data which may adequately capture interaction between oil and stock prices in the region. We do not use daily data in order to avoid time difference problems with international markets. In fact, the equity markets are generally closed on Thursdays and Fridays in GCC countries, while the developed and international oil markets close for trading on Saturdays and Sundays. Furthermore, for the common open days, the GCC markets close just before US stock and commodity markets open. Accordingly, we opt to use weekly data and choose Tuesday as the weekday for all variables because this day lies in the middle of the three common trading days for all markets. 
Furthermore, the data used in all the analyses predate the end of 2005, and thus previous studies missed the spectacular evolutions that took place in the GCC and oil markets in the last three years. Therefore, our sample period goes from 7 June 2005 to 21 October 2008 for the six GCC members and the world stock market measured by the MSCI world market index. Stock market indices are obtained from MSCI database. For oil, we use the weekly Brent spot price obtained from the Energy Information Administration (EIA). Brent oil prices are often used as reference prices for crude oil including oil produced by GCC countries. All prices are denominated in American dollar. Descriptive statistics for return series are summarized in Table 1.

Insert Table 1 Here

Compared to world market, GCC stock markets have higher volatilities, but not necessarily higher returns. Kuwait has the highest weekly returns followed by Oman. Saudi Arabia has the highest volatility followed by Qatar. Oil prices have on average increased more than all GCC stock markets over our sample period. Skewness is negative in most cases and the Jarque-Bera test statistic (JB) strongly rejects the hypothesis of normality, except for Kuwait.

Panel B reports the unconditional correlations among GGG markets, MSCI and oil prices. As we can see, cross-market correlations of GCC stock returns and oil prices are not high but on average higher than correlation between oil prices and MSCI. Two countries have negative correlations with oil price changes: Bahrain and Kuwait. Correlation between GCC markets and world market are low and negative, except for Oman and Saudi Arabia. This suggests that GCC stock markets are segmented from international stock markets. This is indicative of the facts these markets are generally disconnected from the world market trends, and global investors can still benefit from adding financial assets of the Gulf region in their diversified portfolios.

\section{Methodology and empirical results}

We use different international multifactor models in order to examine whether GCC stock markets are sensitive to oil price and world market changes. In this section, we present the specifications we finally retained and discuss our main findings.

\section{Linear model:}

In order to investigate the short-term link between oil prices and stock market returns in GCC countries, we first examine the following simple linear model:

$$
r_{t}=a+b \text { roil }_{t}+c \text { rmsci }_{t}+\varepsilon_{t}
$$

where $r_{t}$ is the weekly stock return in country $\mathrm{i}$, roil $_{t}$ and $r m s c i_{t}$ are the weekly Brent oil price changes and world stock market returns, respectively.(Note 1) We introduce a constant and the world market return in the model we estimate in order to take into account the average effect of the variables omitted in equation (1).

The model is estimated using the OLS method. The results of our estimations are summarized in Table 2.

Insert Table 2 Here

World market returns play a significant role in explaining the stock return structures only in the cases of Oman and Saudi Arabia. Thus, as we expected most GCC stock markets are segmented from world market. They offer high international portfolio diversification opportunities for investors from developed and emerging countries. More interestingly, the coefficients relating the return series to oil price changes are significant for Oman, Qatar and UAE. These coefficients are positive indicating positive reaction of the stock markets in these countries to oil price shocks. Our results show that there is no short tern relationship between oil price changes and stock returns in Bahrain, Kuwait and Saudi Arabia.

The absence of relationships between oil prices and stock markets in too oil dependent economies such as Saudi Arabia seems to be counterintuitive. However, as we have previously mentioned, some recent papers have shown that the link between oil price and economic activity is not entirely linear and that there is some evidence of nonlinearities between the two variables [Hamilton (2003), Zhang (2008) and Lardic and Mignon (2006, 2008)]. Therefore, one possible explanation for our findings is that the traditional linear specifications are too restrictive and cannot reproduce such nonlinearities.

In the rest of the paper, we investigate whether our results are not conditioned to the assumption of a linear relationship. More precisely, we use the nonlinear regression model. The nonlinearity is of the threshold type. There are mixed results about the signs of the correlation between oil price and stock market returns. Some studies found a significant negative correlation. Others argued for a significant positive correlation about these two series, in particular after each crisis period. The use of threshold models allows the correlation between oil price and stock market returns to vary according to the value taken by the threshold variable. In the present paper, we use oil price changes as threshold variable. This allows to assess the extend to which the correlation between oil prices and stock market returns in the 
GCC countries keeps the same sign (positive or negative), significance (significant or not) and value when oil prices move over time. Huang et al. (2005) showed that when oil price change and volatility exceed a threshold, they possess significant explanatory power for the outcome of economic variables such as industrial production and stock market returns.

\section{Non-linear model:}

The model to be estimated is written as follows:

$$
r_{i t}=\left(a_{1}+b_{1} \text { roil }_{t}+c_{1} \text { rmsci }_{t}\right) 1\left(q_{t} \leq \gamma\right)+\left(a_{2}+b_{2} \text { roil }_{t}+c_{2} \text { rmsci }_{t}\right) 1\left(q_{t}>\gamma\right)+\varepsilon_{i t}
$$

where 1(.) denotes the indicator function, and $q_{t}$ is a known function of the data and $\gamma$ is the threshold parameter and the error $\varepsilon_{t}$ is iid $\left(0, \sigma^{2}\right)$.

The parameters of interest to be estimated are $\theta=\left(a_{i} b_{i} c_{i}\right)^{\prime}$ and $\gamma$. We use the sequential conditional LS method to estimate the parameter vector. This method is equivalent to the maximum likelihood one since the errors $\varepsilon_{t}$ are iid. If we denote by $y_{t}$ the vector of endogenous variables and $x_{t}$ the vector of exogenous variables, thus for a given value of $\gamma$, the LS estimate of $\theta$ is :

$\hat{\theta}=\left(\sum_{t=1}^{n} x_{t}(\gamma) x_{t}(\gamma)^{\prime}\right)^{-1}\left(\sum_{t=1}^{n} x_{t}(\gamma) y_{t}\right)$

with $\mathrm{n}$ is the data sample size and $x_{t}(\gamma)=\left(x_{t}^{\prime} 1\left(q_{t} \leq \gamma\right) \quad x_{t}^{\prime} 1\left(q_{t}>\gamma\right)^{\prime}\right.$.

The residual variance $\hat{\sigma}_{n}^{2}(\gamma)$ is calculated as follows:

$\sigma_{n}^{2}(\gamma)=\frac{1}{n} \sum \hat{\varepsilon}_{t}^{2}(\gamma)$

where $\hat{\varepsilon}_{t}(\gamma)=y_{t}-x_{t}(\gamma)^{\prime} \hat{\theta}(\gamma)$.

The LS estimate of $\gamma$ is the one minimizing the $\hat{\sigma}_{n}^{2}(\gamma)$ according to:

$\hat{\gamma}=\underset{\gamma}{\arg \min } \hat{\sigma}_{n}^{2}(\gamma)$

with $\gamma \in \Gamma=[\gamma, \bar{\gamma}] . \Gamma$ is obtained by discarding $15 \%$ from both sides of the empirical distribution of the threshold variable $q_{t}$.(Note 2 ) To test for threshold effect in the regression above we use the following Likelihood Ratio (LR) statistic:

$\operatorname{LR}_{n}(\gamma)=n\left(\frac{\hat{\sigma}_{n}^{2}(\gamma)-\hat{\sigma}_{n}^{2}(\hat{\gamma})}{\hat{\sigma}_{n}^{2}(\hat{\gamma})}\right)$

Figure 1 displays the sequence of LR statistic for all values of $\gamma \in \Gamma$. The dashed lines represent the 95\% confidence interval of the LR statistic. Results show that a threshold effect exists in the slope parameters of the linear regression. Insert Figure 1 Here

The results of our estimations are reported in Table 3.

Insert Table 3 Here

Let's start by the Omani stock market. The link between oil and stock returns is positively significant in the two regimes. However, the elasticity of stock returns to oil price changes is higher in the first regime. In this paper first regime refers to the case where $q_{t} \leq \gamma$ and second regime to the case $q_{t}>\gamma$.

For Qatar and UAE, we found two different regimes. In the first one, oil price changes negatively affect stock returns, while in the second regime stock returns and oil price changes are positively linked. In all cases, the coefficients of the world market returns are significant at least in one regime. 
Next, consider the three markets we have not found to be significantly related to oil price fluctuations within the linear framework: Bahrain, Kuwait and Saudi Arabia. The results do not seem to significantly change for Kuwait and Bahrain. Again, there is no significant link between oil and stock markets in these two countries. Conversely, while our linear estimates suggest that stock markets in Bahrain and Kuwait are totally segmented from the world market, our nonlinear estimates show that the coefficients relating the Bahraini and Kuwaiti stock returns to the world market returns are positively significant in the first regime, suggesting that these two markets are partially nonlinearly integrated into the world market.

Our findings are more interesting for Saudi Arabia. In fact, for this stock market, we show a highly significant negative link between oil price changes and stock returns in the first regime, but a weakly positive link in the second regime. This finding suggests that the relationship between the Saudi stock market and the oil prices is not linear and its sign changes according to oil price levels.

Using the MSCI return series as threshold variable, unreported results show two regimes for Qatar and Saudi Arabia. For these two countries the estimated thresholds are $\hat{\gamma}=-0.001$ and $\hat{\gamma}=0.023$. For UAE and Oman results show that the impact of oil price on stock market returns is statistically significant only in the second regime i.e the MSCI return is higher than -0.033 for UAE and -0.006 for Oman. In both countries the correlation between oil price and stock market returns is significantly positive in the second regime. Results remain unchanged for Kuwait and Bahrain relative to the use of oil price as threshold variable.

Taken together, our results suggest that oil price changes affect stock market returns in GCC countries in a nonlinear manner. These findings may reflect the complexity of the transmission mechanisms of oil price shocks to stock markets in GCC countries. In fact, oil price increases directly affect government and corporate output and earnings in GCC countries and thus may positively affect stock market returns. However, GCC countries are importers of manufactories products from developed and emerging countries. Therefore, oil price increases can indirectly impact GCC markets through their influence on prices of imported products and then increases in oil prices are often indicative of inflationary pressure in the GCC economies which in turn could indicate the future of interest rates and investment of all types. Therefore, unlike net oil importing countries where the expected link between oil prices and stock markets is negative, the transmission mechanism of oil price shocks to stock market returns are ambiguous and the total impact of oil price shocks on stock returns depends on which of the positive and negative effects counterweigh the other. Our findings confirm partly this opinion and suggest that the sign of the impact of oil changes on stock returns in GCC markets change from one regime to another according to oil price changes.

\section{Conclusion and policy implications}

In this article, we extend the understanding of the responses of stock markets in GCC countries to oil price shocks. Since GCC countries are major world energy market players, their stock markets are likely to be sensitive to oil price changes. We test for both linear and nonlinear linkages. Our findings show that stock market returns significantly react to oil price changes in Qatar, Oman, Saudi Arabia and UAE. In addition, we establish that the relationships between oil prices and stock markets in these countries are nonlinear and switching according to the oil price values. However, for Bahrain and Kuwait we found that oil price changes do not affect stock market returns. Our results should be of interest to researchers, regulators, and market participants. In particular, GCC countries as policy makers in OPEC should keep an eye on the effects of oil price fluctuations on their own economies and stock markets. For investors, the significant relationship between oil prices and stock market returns implies some degree of predictability in the GCC stock markets.

The findings of this paper offer several avenues for future research. First, the link between oil and stock markets in GCC countries can be expected to vary across different economic sectors. A sectoral analysis of this link would be informative. Second, evidence from international equity markets should be produced to examine the robustness of the findings. Third, the methodology applied in this article could be used to examine the effects of other energy products such as gaz. Finally, further research could compare causality between oil and stock markets in GCC countries and other oil exporting countries.

\section{References}

Ackert L., Church B. \& Engils B. (2002). The asset allocation decision \& investor heterogeneity: a puzzle? Journal of Economic Behaviour and Organization, vol. 47, pp. 423-433

Adler M. \& Dumas B. (1983). International Portfolio Choice and Corporation Finance: A Synthesis. The Journal of Finance, vol. 38, no 3, pp. 925-984.

Alain Coen (2001). Home bias and international capital asset pricing model with human capital. Journal of Multinational Financial Management, Volume 11, Issues 4-5, December 2001, pp. 497-513 
Alan A., William L. Griever \& Francis E. Warnock. (2004). Information costs and home bias: An analysis of U.S. holdings of

Arouri M. and Fouquau J. (2009). On the short-term influence of oil price changes on stock markets in GCC countries: linear and nonlinear analyses. Economics Bulletin, Vol. 29 no.2, pp. 806-815

Balaz, P. and Londarev, A. (2006). Oil and its position in the process of globalization of the world economy. Politicka Ekonomie, 54 (4), 508-528

Bashar, Z. (2006). Wild oil prices, but brave stock markets! The case of Gulf Cooperation Council (GCC) stock markets. Middle East Economic Association Conference, Dubai.

Bashar, Z. (2006). Wild oil prices, but brave stock markets! The case of Gulf Cooperation Council (GCC) stock markets. Middle East Economic Association Conference, Dubai

Basher, S. A. and Sadorsky, P. (2006). Oil Price Risk and Emerging Stock Markets. Global Finance Journal, 17, 224-251

CINER C. (2001). Energy Shocks and Financial Markets: Nonlinear Linkages. Studies in Nonlinear Dynamics \& Econometrics: Vol. 5: No. 3. 203-212

Cologni, A. and Manera M. (2008). Oil prices, inflation and interest rates in a structural cointegrated VAR model for the G-7 countries. Energy Economics, 30, 856-88.

Cologni, A. and Manera M. (2009). The Asymmetric Effects of Oil Shocks on Output Growth: A Markov-Switching Analysis for the G-7 Countries. Economic Modelling, 26, 1-29.

Cunado, J., Perez de Garcia, F. (2005). Oil prices, economic activity and inflation: evidence for some Asian countries. The Quarterly Review of Economics and Finance 45 (1), 65-83.

Gronwald, M. (2008). Large oil shocks and the US economy: Infrequent incidents with large effects. Energy Journal, $29,151-71$

Hamilton, J. D. (2003). What is an Oil Shock?. Journal of Econometrics, 113, pp. 363-98

Hammoudeh, S. and Aleisa, E. (2004). Dynamic relationship among GCC stock markets and NYMEX oil futures. Contemporary Economic Policy, Vol. 22, pp.250-269

Hammoudeh, S. and Choi, K. (2006). Behavior of GCC Stock Markets and Impacts of US Oil and Financial Markets. Research in International Business and Finance, Vol. 20 no. 1,pp. 22-44.

Hansen B. (1997). Inference in tar models. Studies in Nonlinear Dynamics and Econometrics, vol. 2(1), pp. 1-14

Huang, B.N., Hwang, M. J., and Peng, H.P. (2005). The asymmetry of the impact of oil price shocks on economic activities: An application of the multivariate threshold model. Energy Economics 27, pp.445-476

Huang, R. D., Masulis, R. W., and Stoll H. R. (1996), Energy shocks and financial markets. Journal of Futures Markets, 16, 1-27

Jones, C.M. and Kaul, G. (1996). Oil and the Stock Markets. Journal of Finance, vol. 51, no 2, pp. 463-491.

Kilian, L. (2008). Exogenous Oil Supply Shocks: How Big Are They and How Much Do They Matter for the US Economy?. Review of Economics and Statistics, 90, 216-40

Lardic S. and Mignon V. (2006). The impact of oil prices on GDP in European countries: An empirical investigation based on asymmetric cointegration. Energy Policy, vol. 34(18), pp. 3910-3915

Lardic S. and Mignon V. (2008). Oil prices and economic activity: An asymmetric cointegration approach. Energy Economics, vol. 30(3), pp. 847-855

Maghyereh A. and Al-Kandari A. (2007). Oil prices and stock markets in GCC countries: new evidence from nonlinear cointegration analysis. Managerial Finance, 33(7), pp. $449-460$

Papapetrou, E. (2001). Oil Price Shocks, Stock Market, Economic Activity and Employment in Greece. Energy Economics, 23, 511-32

Sadorsky, P. (1999). Oil Price Shocks and Stock Market Activity. Energy Economics, vol. 2, pp. 449-469

Zhang D. (2008). Oil shock and economic growth in Japan: A nonlinear approach. Energy Economics, vol. 30, issue 5, pages pp. $2374-2390$ 
Table 1. Descriptive statistics

Panel A: Basic statistics

\begin{tabular}{lcccccccc}
\hline \hline & Bahrain & Kuwait & Oman & Qatar & A. Saudi & UAE & MSCI & Oil \\
\hline Mean & 0.0004 & 0.0032 & 0.0014 & 0.0012 & -0.0015 & -0.0013 & 0.0010 & 0.0047 \\
Std. errors & 0.0246 & 0.0268 & 0.0274 & 0.0362 & 0.0492 & 0.0350 & 0.0185 & 0.0311 \\
Skewness & 0.7884 & -0.0934 & -0.1347 & 0.1911 & -1.3440 & -0.3865 & -0.6323 & -0.2571 \\
Kurtosis & 6.6975 & 3.2524 & 4.3106 & 4.4806 & 7.8225 & 5.0094 & 3.7703 & 2.6373 \\
JB & $114.27^{*}$ & 0.6991 & $12.6812^{*}$ & $16.5646^{*}$ & $215.920^{*}$ & $32.8352^{*}$ & $15.5326^{*}$ & 2.8014 \\
\hline \hline Panel B: Unconditional correlations & & & & & & \\
\hline \hline & Bahrain & Kuwait & Oman & Qatar & A. Saudi & UAE & MSCI \\
\hline Oil & -0.017 & -0.072 & 0.126 & 0.300 & 0.110 & 0.147 & 0.058 \\
MSCI & -0.005 & -0.073 & 0.079 & -0.085 & 0.032 & -0.005 & --- \\
\hline \hline
\end{tabular}

Notes: The test for Kurtosis coefficient has been normalized to zero. JB is the Jarque-Bera test for normality based on excess skewness and Kurtosis.. ${ }^{*},{ }^{* *}$ and ${ }^{* * *}$ indicate significance of coefficients at the $10 \%, 5 \%$ and $1 \%$ level, respectively.

Table 2. Estimates results- linear models

\begin{tabular}{|c|c|c|c|c|c|c|}
\hline & Bahrain & Kuwait & Oman & Qatar & A. Saudi & UAE \\
\hline \multirow[t]{2}{*}{$a$} & -0.001 & 0.003 & 0.000 & -0.001 & -0.003 & -0.004 \\
\hline & $(0.002)$ & $(0.002)$ & $(0.002)$ & $(0.003)$ & $(0.004)$ & $(0.003)$ \\
\hline \multirow[t]{2}{*}{$b$} & 0.021 & -0.043 & 0.170 & 0.388 & 0.101 & 0.284 \\
\hline & $(0.054)$ & $(0.059)$ & $(0.060)$ & $(0.078)$ & $(0.107)$ & $(0.084)$ \\
\hline \multirow[t]{2}{*}{$c$} & 0.172 & 0.109 & 0.303 & 0.154 & 0.297 & 0.430 \\
\hline & $(0.074)$ & $(0.082)$ & $(0.083)$ & $(0.108)$ & $(0.148)$ & $(0.116)$ \\
\hline$R^{2}$ & 0.022 & 0.000121 & 0.122 & 0.140 & 0.021 & 0.143 \\
\hline Log Liklihood & 398.837 & 382.847 & 379.688 & 332.780 & 277.991 & 320.872 \\
\hline AIC & -4.498 & -4.316 & -4.280 & -3.747 & -3.125 & -3.612 \\
\hline
\end{tabular}

Notes: ${ }^{* * *}$ and ${ }^{* * *}$ indicate significance of coefficients at the $10 \%, 5 \%$ and $1 \%$ respectively. Robust standard errors are given between parentheses. 
Table 3. Estimates results - nonlinear models

\begin{tabular}{|c|c|c|c|c|c|c|}
\hline & Bahrain & Kuwait & Oman & Qatar & A. Saudi & UAE \\
\hline$\hat{\gamma}$ & $\begin{array}{c}-0.048 \\
{[-0.060,-0.044]} \\
\end{array}$ & $\begin{array}{c}-0.082 \\
{[-0.082,-0.082]}\end{array}$ & $\begin{array}{c}-0.039 \\
{[-0.082,0.031]}\end{array}$ & $\begin{array}{c}-0.060 \\
{[-0.076,-0.060]}\end{array}$ & $\begin{array}{c}-0.076 \\
{[-0.076,-0.076]}\end{array}$ & $\begin{array}{c}-0.060 \\
{[-0.060,-0.060]}\end{array}$ \\
\hline$a_{1}$ & $\begin{array}{c}0.027 \\
(0.028)\end{array}$ & $\begin{array}{c}0.028 \\
(0.052)\end{array}$ & $\begin{array}{c}0.040 \\
(0.018)\end{array}$ & $\begin{array}{l}-0.068 \\
(0.052)\end{array}$ & $\begin{array}{l}-0.218 \\
(0.090)\end{array}$ & $\begin{array}{l}-0.099 \\
(0.118)\end{array}$ \\
\hline$b_{1}$ & $\begin{array}{c}0.284 \\
(0.354)\end{array}$ & $\begin{array}{c}0.069 \\
(0.487)\end{array}$ & $\begin{array}{c}0.638 \\
(0.272)\end{array}$ & $\begin{array}{l}-0.328 \\
(0.535)\end{array}$ & $\begin{array}{l}-2.104 \\
(0.871)\end{array}$ & $\begin{array}{l}-0.568 \\
(1.152)\end{array}$ \\
\hline$c_{1}$ & $\begin{array}{c}0.414 \\
(0.165)\end{array}$ & $\begin{array}{c}0.415 \\
(0.140)\end{array}$ & $\begin{array}{c}0.463 \\
(0.148)\end{array}$ & $\begin{array}{c}0.779 \\
(0.191)\end{array}$ & $\begin{array}{c}0.780 \\
(0.271)\end{array}$ & $\begin{array}{c}1.191 \\
(0.358)\end{array}$ \\
\hline$\overline{R^{2}}$ & 0.318 & 0.664 & 0.455 & 0.717 & 0.633 & 0.656 \\
\hline Log Liklihood & 27.009 & 12.930 & 45.425 & 14.606 & 10.877 & 9.201 \\
\hline AIC & -3.43 & -3.972 & -3.689 & -3.316 & -2.626 & -2.067 \\
\hline \multicolumn{7}{|l|}{ Régime 2} \\
\hline$a_{2}$ & $\begin{array}{r}0.000 \\
(0.002)\end{array}$ & $\begin{array}{c}0.002 \\
(0.002)\end{array}$ & $\begin{array}{l}-0.001 \\
(0.002)\end{array}$ & $\begin{array}{c}0.000 \\
(0.003)\end{array}$ & $\begin{array}{l}-0.003 \\
(0.004)\end{array}$ & $\begin{array}{l}-0.002 \\
(0.003)\end{array}$ \\
\hline$b_{2}$ & $\begin{array}{c}0.003 \\
(0.064)\end{array}$ & $\begin{array}{l}-0.032 \\
(0.067)\end{array}$ & $\begin{array}{c}0.200 \\
(0.080)\end{array}$ & $\begin{array}{c}0.359 \\
(0.088)\end{array}$ & $\begin{array}{c}0.149 \\
(0.124)\end{array}$ & $\begin{array}{c}0.183 \\
(0.089)\end{array}$ \\
\hline$c_{2}$ & $\begin{array}{l}-0.123 \\
(0.101)\end{array}$ & $\begin{array}{l}-0.101 \\
(0.104)\end{array}$ & $\begin{array}{c}0.089 \\
(0.116)\end{array}$ & $\begin{array}{l}-0.260 \\
(0.133)\end{array}$ & $\begin{array}{c}0.104 \\
(0.194)\end{array}$ & $\begin{array}{l}-0.105 \\
(0.134)\end{array}$ \\
\hline$R^{2}$ & -0.003 & -0.004 & 0.030 & 0.092 & -0.001 & 0.015 \\
\hline Log Liklihood & 383.560 & 375.734 & 343.484 & 330.361 & 272.678 & 329.829 \\
\hline AIC & -4.692 & -4.359 & -4.451 & -3.874 & -3.173 & -3.868 \\
\hline
\end{tabular}

Notes: ${ }^{*},{ }^{* *}$ and ${ }^{* * *}$ indicate significance of coefficients at the $10 \%, 5 \%$ and $1 \%$ respectively. Robust standard errors are into parentheses.

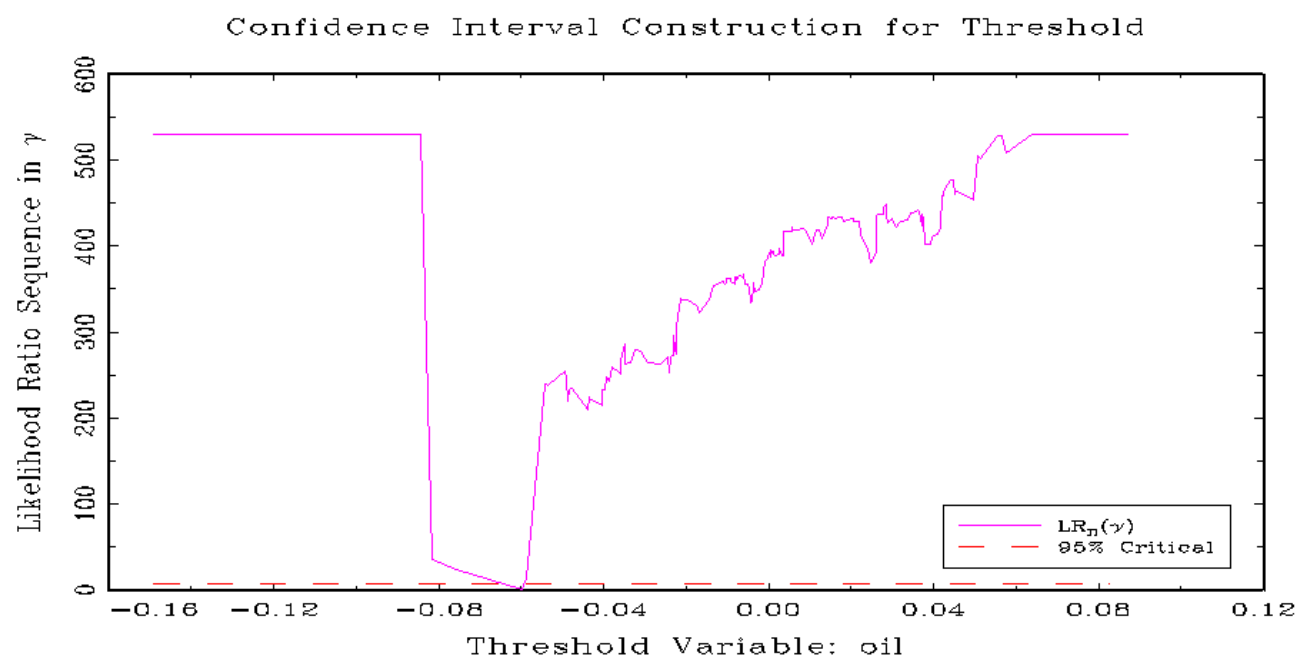

Figure 1. 